\title{
Expression of prophage-encoded endolysins contributes to autolysis of Lactococcus lactis
}

\author{
Ganesh Ram R. Visweswaran ${ }^{1,3} \cdot$ Dorota Kurek $^{1} \cdot$ Monika Szeliga $^{1} \cdot$ \\ Francisco Romero Pastrana $^{2}$ • Oscar P. Kuipers ${ }^{1} \cdot$ Jan Kok $^{1}$ • Girbe Buist ${ }^{1,2}$
}

Received: 4 July 2016 /Revised: 14 August 2016 / Accepted: 16 August 2016 / Published online: 22 September 2016

(C) The Author(s) 2016. This article is published with open access at Springerlink.com

\begin{abstract}
Analysis of autolysis of derivatives of Lactococcus lactis subsp. cremoris MG1363 and subsp. lactis IL1403, both lacking the major autolysin AcmA, showed that L. lactis IL1403 still lysed during growth while L. lactis MG1363 did not. Zymographic analysis revealed that a peptidoglycan hydrolase activity of around $30 \mathrm{kDa}$ is present in cell extracts of L. lactis IL1403 that could not be detected in strain MG1363. A comparison of all genes encoding putative peptidoglycan hydrolases of IL1403 and MG1363 led to the assumption that one or more of the $99 \%$ homologous $27.9-\mathrm{kDa}$ endolysins encoded by the prophages bIL285, bIL286 and bIL309 could account for the autolysis phenotype of IL1403. Induced expression of the endolysins from bIL285, bIL286 or bIL309 in L. lactis MG1363 resulted in detectable lysis or lytic activity. Prophage deletion and insertion derivatives of L. lactis IL1403 had a reduced cell lysis phenotype. RT-qPCR and zymogram analysis showed that each of these strains still expressed one or more of the three phage lysins. A homologous gene and an endolysin activity were also identified in the natural starter
\end{abstract}

Electronic supplementary material The online version of this article (doi:10.1007/s00253-016-7822-z) contains supplementary material, which is available to authorized users.

Jan Kok

jan.kok@rug.nl

1 Department of Molecular Genetics, Groningen Biomolecular Sciences and Biotechnology Institute (GBB), University of Groningen, Nijenborgh 7, 9747, AG Groningen, the Netherlands

2 Department of Medical Microbiology, University of Groningen, University Medical Centre Groningen, Hanzeplein 1, 9700 Groningen, RB, the Netherlands

3 Present address: Department of Immunology, University of Oslo, Rikshospitalet, Sognsvannsveien 20, 0372 Oslo, Norway culture L. lactis subsp. cremoris strains E8, Wg2 and HP, and the lytic activity could be detected under growth conditions that were identical as those used for IL1403. The results presented here show that these endolysins of $L$. lactis are expressed during normal growth and contribute to autolysis without production of (lytic) phages. Screening for natural strains expressing homologous endolysins could help in the selection of strains with enhanced autolysis and, thus, cheese ripening properties.

Keywords Autolysis · Bacteriophage $\cdot$ Endolysins · Lactococcus lactis

\section{Introduction}

A balanced action of peptidoglycan (PG) synthesis and degradation is essential for bacterial growth. To be able to grow and divide, bacteria express PG hydrolases that open up the rigid PG saccules (Vollmer et al. 2008). PG hydrolases play amongst others important roles in cell division and separation, cell wall turnover, PG modifications, sporulation, competence development, flagella formation and the activity of some antibiotics (Vollmer et al. 2008).

The glycan chains of PG can be cleaved by $N$ acetylglucosaminidases or $\mathrm{N}$-acetylmuramidases. $\mathrm{N}$ acetylmuramoyl-L-alanine amidases (amidases) hydrolyse the bond between the glycan chain and the pentapeptide side chain, while carboxypeptidases and endopeptidases can cleave the different bonds of the peptide side chain. For instance, DD-carboxypeptidases remove the terminal D-alanine residues of a pentapeptide to form a tetrapeptide thereby generating an acceptor for interpeptide bridge formation. Some endopeptidases cleave within the interpeptide bridge that can be present between two peptide side chains (Vollmer et al. 
2008). Autolysis of cells is the result of the uncontrolled action of PG hydrolases when cell wall assembly and/or repair are inhibited (Vollmer et al. 2008). Because autolysins are potentially lethal enzymes, their activity has to be tightly regulated. Regulation can occur at the transcriptional and at the translational level, but it mostly operated at the posttranslational level such as by maturation of a preenzyme by the action of proteases or via controlled binding to the PG.

The gram-positive lactic acid bacterium Lactococcus lactis expresses four $N$-acetylglucosaminidases, namely AcmA, $\mathrm{AcmB}, \mathrm{AcmC}$ and AcmD, that share a homologous active site domain (Buist et al. 1997; Huard et al. 2003, 2004; Visweswaran et al. 2013). AcmA is required for cell separation and is the major autolysin that is responsible for lysis during the stationary phase of growth of L. lactis (Buist et al. 1995). An acmA mutant of L. lactis MG1363 has been shown to completely lose autolysis activity under laboratory conditions, while overexpression of AcmA resulted in increased lysis (Buist et al. 1997; Steen et al. 2007, 2005a).

AcmD contributes to cell separation and autolysis although these actions are dependent on the presence of AcmA activity (Visweswaran et al. 2013). Inactivation of $a \mathrm{~cm} B$ revealed that $A c m B$ of $L$. lactis might also be involved in autolysis since the mutant lysed to a lesser extent than its parent $L$. lactis MG1363. The effect was dependent on the presence of AcmA activity as no effect on autolysis of $a \mathrm{~cm} B$ was observed in an acmAB double mutant of L. lactis MG1363 (Huard et al. 2003). AcmD and AcmA both contain three C-terminal LysM sequences that are needed for peptidoglycan binding (Visweswaran et al. 2013). The presence of cell wall constituents like LTA, S-layer proteins or peptidoglycan modifications such as increased $O$-acetylation or reduced Dalanylation has been shown to inhibit binding of LysM and therefore prevent undesired enzymatic activity of AcmA (Steen et al. 2003; Veiga et al. 2007; Buist et al. 2008). Nacetylglucosamine deacetylation of $\mathrm{PG}$ has been shown to decrease autolysis in L. lactis (Meyrand et al. 2007). Degradation of AcmA by the membrane-located protease $\mathrm{HtrA}$ and/or the extracellular proteinase PrtP of L. lactis directly affects the degree of autolysis (Buist et al. 1998; Bosma et al. 2006).

Besides the genome-encoded PG hydrolases, the expression of endolysins can also contribute to (auto)lysis of lactococcal cells. Phage-encoded lysins function in the release of phages from the host cells (Vollmer et al. 2008). Such endolysins are generally co-expressed with holins that form pores in the cytoplasmic membrane of the host, thereby abolishing membrane potential and translocating the endolysin over the membrane (Young 2002).

L. lactis is one of the main bacterial species used in the production of cheese. One of the most important steps in cheese ripening is the release of intracellular proteolytic enzymes into the cheese matrix, which is a result of (auto)lysis of the lactococcal cells (Steen et al. 2007). Steen et al. (2007) have compared AcmB, AcmC, AcmD, endopeptidase YjgB and endolysin from prophages bIL309 and LytR from bacteriophage $\mathrm{r} 1 \mathrm{t}$ with respect to their ability to lyse $L$. lactis cells (Steen et al. 2007). All PG hydrolases were active when expressed in L. lactis. The lysis effect of the activities of $\mathrm{AcmB}, \mathrm{AcmD}$ and $\mathrm{YjgB}$ was dependent on the presence of AcmA. Food-grade overexpression of LytR from the producer strain in conjunction with a starter strain to make Gouda-type cheese resulted in increased lysis of both strains (Steen et al. 2007).

In this report, we investigated the question whether the increased lysis of L. lactis IL1403 compared to strain MG1363 under identical conditions of growth may be due to the presence of an extra lytic activity that was discovered by exclusion analysis of the predicted PG hydrolase content of both strains. The expression of the IL1403 gene for this extra lytic activity in MG1363 resulted in increased lysis of the overexpressing strain indicating that the PG hydrolase contributes to lysis.

\section{Materials and methods}

\section{Bacterial strains, plasmids and growth conditions}

The strains and plasmids used in this study are listed in Table 1. L. lactis was grown in M17 broth (Difco, Becton Dickinson, France) at $30^{\circ} \mathrm{C}$ as standing cultures or on M17 agar. M17 was supplemented with $0.5 \%$ glucose (GM17). Erythromycin and chloramphenicol (both from Roche, Mannheim, Germany) were added to concentrations of $5 \mu \mathrm{g} /$ $\mathrm{ml}$, when needed.

\section{(Quantitative) polymerase chain reaction}

Polymerase chain reactions (PCRs) were performed in a Mastercycler gradient (Eppendorf, Nijmegen, the Netherlands) by using Taq DNA polymerase or Expand DNA polymerase according to the instructions of the manufacturer (Roche). The primer pairs used in RT-qPCR for the detection of the endolysin genes and their messenger RNA (mRNA) transcripts of the bacteriophages bIL286, bIL285 and bIL309, respectively, are presented in Suppl. Table S1. RNA was isolated from $L$. lactis strains at the midexponential phase of growth by using High Pure RNA Isolation Kit (Roche) and according to the manufacturer's protocol (Roche), followed by reverse trascription to generate complementary DNA (cDNA) by using MMLV Reverse Transcriptase (Fermentas GmbH, St. Leon-Rot, Germany). RT-qPCR was performed by using cDNA obtained from different strains, specific primers and SYBR Green RT-qPCR master mix as suggested by the manufacturer (Fermentas 
Table 1 Bacterial strains and plasmids used in this study

\begin{tabular}{|c|c|c|}
\hline Strain or plasmid & Relevant phenotype or genotype & Reference or source \\
\hline \multicolumn{3}{|c|}{ L. lactis subsp. cremoris } \\
\hline MG1363 & $\begin{array}{l}\text { Lactose }(\mathrm{Lac})^{-} \text {, Proteinase }(\mathrm{Prt})^{-} \text {; plasmid-free } \\
\quad \text { derivative of NCDO712 }\end{array}$ & Gasson (1983) \\
\hline MG1363acmA $\Delta 1$ & $\begin{array}{l}\text { Derivative of MG1363 carrying a 701-bp SacI-SpeI } \\
\text { deletion in } \text { acmA }\end{array}$ & Buist et al. (1995) \\
\hline NZ9000 & MG1363 pepN::nisRK & Kuipers et al. (1998) \\
\hline $\mathrm{NZ9000acmA \Delta l}$ & $\begin{array}{l}\text { Derivative of NZ9000 carrying a 701-bp SacI/SpeI } \\
\text { deletion in } a c m A\end{array}$ & Steen et al. (2007) \\
\hline PA1001 & $\begin{array}{l}\text { MG1363 pepN::nisRK, allows nisin-inducible } \\
\text { expression, } \Delta \text { acmA } \Delta \text { trA }\end{array}$ & Bosma et al. (2006) \\
\hline NZ9700 & $\begin{array}{l}\text { Nisin-producing transconjugant containing the } \\
\text { nisin-sucrose transposon Tn } 5276\end{array}$ & Kuipers et al. (1993) \\
\hline E8 & $\mathrm{Prt}^{+}$wildtype & Kok (1990) \\
\hline E8 & $\mathrm{Prt}^{-}$wildtype & Kok (1990) \\
\hline Wg2 & $\mathrm{Prt}^{+}$wildtype & Kok et al. (1985) \\
\hline Wg2 & Prt $^{-}$wildtype & Kok et al. (1985) \\
\hline HP & $\mathrm{Prt}^{+}$wildtype & Kok et al. (1985) \\
\hline HP & Prt $^{-}$wildtype & Kok et al. (1985) \\
\hline \multicolumn{3}{|l|}{ L. lactis subsp. lactis } \\
\hline IL1403 & Plasmid-free derivative of IL594, $\mathrm{Lac}^{-} \mathrm{Prt}^{-}$ & Chopin et al. (1984) \\
\hline IL1403acmA::ISS1 & IL1403with an ISS1 insertion in $\mathrm{acm} A$ & Steen et al. (2008) \\
\hline IL1946 & $\begin{array}{l}\text { IL1403 cured of bIL285 via DCO deletion using } \\
\text { plasmid pE194 }\end{array}$ & Chopin et al. (1989) \\
\hline IL2005 & $\begin{array}{l}\text { Partial deletion of bIL285 following the insertion of } \\
\text { pE194; bIL286 is no more inducible; } \mathrm{Em}^{\mathrm{r}}\end{array}$ & $\begin{array}{l}\text { Institut National de la } \\
\text { Recherche } \\
\text { Agronomique (INRA } \\
\text { collection) }\end{array}$ \\
\hline IL6047 & IL2005 cured of bIL309 & INRA collection \\
\hline pNG8048e & $\begin{array}{l}\text { Derivative of pNZ8048 carrying } \mathrm{Em}^{\mathrm{R}} \text { marker and } \\
\text { the nisin-inducible } \mathrm{P}_{\text {nis }} \text { promoter }\end{array}$ & Steen et al. (2007) \\
\hline pNGbil & $\begin{array}{l}\text { pNG8048e derivative carrying pil } 49 \text { from } \\
\text { prophage bIL309 }\end{array}$ & Steen et al. (2007) \\
\hline pNGbil::pi252 & $\begin{array}{l}\text { pNG8048e derivative carrying pi252 from } \\
\text { prophage bIL } 285\end{array}$ & This study \\
\hline pNGbil::pi305 & $\begin{array}{l}\text { pNG8048e derivative carrying pi305 from } \\
\text { prophage bIL } 286\end{array}$ & This study \\
\hline
\end{tabular}

$\mathrm{GmbH})$. The relative mRNA expression levels of different genes were obtained after normalizing to that of the housekeeping gene, the RNA polymerase alpha subunit (rpoA).

\section{Construction of plasmids for the induced expression of endolysins from bIL285 and bIL286}

Plasmids for the expression of the endolysins encoded by the phages bIL285 and bIL286 were constructed by generating PCR fragments of the genes pi252 and pi305, respectively (Phusion Hot Start II, Thermo Fisher Scientific, Wilmington, Delaware USA) by using L. lactis subsp. lactis IL1403 genomic DNA as a template (ZR Fungal/Bacterial DNA MiniPrep, Zymo Research, Irvine, CA, USA) with primers bil285F/ bil286R and bil286F/bil286R. PCR fragment of pi252 was digested with $B s a \mathrm{I}$ to generate cloning overhangs and EcoRV to digest co-amplified pi149 and pi305 PCR fragments. PCR fragment pi305 was digested with BsaI, ApaI and $A f l \mathrm{II}$ restriction enzymes (New England Biolabs,
Ipswich, MA, USA) to generate cloning overhangs and digest co-amplified pi149 and pi252 PCR fragments, respectively. Both digested PCR fragments were inserted into NcoI/ HindIII-linearized vector pNZ8048e. PCR products were purified by using the High Pure PCR Purification Kit (Analytic Jena, Jena, Germany). Ligations were performed by using T4 DNA Ligase (New England Biolabs), and the resulting plasmids were transferred to electrocompetent L. lactis PA1001 as described before (Leenhouts and Venema 1993). All selected plasmids were checked by sequencing (Eurofins MWG Operon, Ebersberg, Germany).

\section{SDS-PAGE, zymogram and Western hybridization}

Cell extracts and supernatant samples were prepared as described before (Buist et al. 1998). For cell fractionation, $25 \mathrm{ml}$ of an overnight culture of L. lactis was subjected to centrifugation. The spent medium fraction was dialysed against several changes of demineralized water, lyophilized 
and dissolved in $800 \mu \mathrm{l}$ of denaturation buffer [ $2 \%$ dithiothreitol, $15 \%$ sucrose, $3.8 \%$ sodium dodecyl sulphate (SDS) (all $w / v)]$. The cell pellet was resuspended in $1 \mathrm{ml}$ of $50 \mathrm{mM}$ sodium phosphate buffer ( $\mathrm{pH}$ 6.5) containing $100 \mathrm{mM} \mathrm{NaCl}$, $550 \mathrm{mM}$ sucrose, $5 \mathrm{mg} / \mathrm{ml}$ lysozyme and $50 \mathrm{U}$ of mutanolysin and incubated for $1 \mathrm{~h}$ at $37^{\circ} \mathrm{C}$. In order to collect the cell wall fraction, the cell suspension was centrifuged at $5000 \times \mathrm{g}$ for $15 \mathrm{~min}$. Eight hundred microlitres of the supernatant fraction was dialysed, lyophilized and dissolved as described for the spent medium fraction. Protoplasts were resuspended in $1 \mathrm{ml}$ of $50 \mathrm{mM}$ sodium phosphate buffer ( $\mathrm{pH}$ 6.5) containing $100 \mathrm{mM} \mathrm{NaCl}$ and subjected to sonication (six pulses of $15 \mathrm{~s}$ spaced $30 \mathrm{~s}$ apart on ice) with a Soniprep 150 Ultrasonic Disintegrator (MSE Scientific Instruments, Sussex, England). Unbroken cells were removed by centrifugation $\left(5000 \times g\right.$ for $15 \mathrm{~min}$ at $\left.4{ }^{\circ} \mathrm{C}\right)$. The supernatant was centrifuged at $30,000 \times \mathrm{g}$ for $30 \mathrm{~min}$. The pellet (membrane fraction) was resuspended in $1 \mathrm{ml}$ of denaturation buffer. The supernatant (cytoplasmic fraction) was dialysed, lyophilized and dissolved as described for the spent medium fraction.

The expression of the phage lysins from bacteriophages bIL285, bIL286 or bIL309 was induced with nisin by the addition of 1/1000 volumes of a supernatant of a culture of the nisin-producing strain L. lactis NZ9700 bearing the plasmid pNG8048e (Steen et al. 2007). PG-degrading activity was detected by a zymogram staining technique by using SDSpolyacrylamide (PAA) (10 or $12.5 \%$ ) gels containing $0.15 \%(w / v)$ autoclaved, lyophilized Micrococcus lysodeikticus ATCC 4698 cells (Sigma-Aldrich, St. Louis, $\mathrm{MO})$ or $0.3 \%(w / v)$ L. lactis IL1403 autoclaved cells as a substrate, as described previously (Buist et al. 1995). To detect all peptidoglycan degradation activities of the endolysins, AcmA and its degradation products simultaneously in all samples, M. lysodeikticus cell wall fragments, were used in most cases. Renaturation of SDS-PAA gels were performed at $\mathrm{pH}$ 7.4. A prestained broad-range SDS-PAGE molecular mass marker of Bio-Rad Laboratories was used as a reference (Bio-Rad, Hercules, CA).

SDS-PAA gels (without cells) were stained with Coomassie brilliant blue (Bio-Rad). For Western hybridizations, proteins were transferred from SDS-PAA gels to polyvinylidene difluoride membranes (Roche) as described by Towbin et al. (1979). AcmA was detected with 1:5000diluted polyclonal rabbit anti-AcmA active site antibodies (Steen et al. 2005b) and 1:5000-diluted HRP-conjugated anti-rabbit antibodies by using the ECL Western Blotting System and protocol (Amersham, Buckinghamshire, UK).

\section{Optical density measurements and enzyme activity assays}

Overnight cultures of L. lactis in M17 were diluted 100-fold in prewarmed $\mathrm{M} 17$ at $30^{\circ} \mathrm{C}$, and the optical densities at $600 \mathrm{~nm}$
$\left(\mathrm{OD}_{600}\right)$ were followed in time by using a Novaspec II spectrophotometer (Pharmacia Biotech AB, Uppsala, Sweden).

For a measure of cell lysis, the presence of intracellular Xprolyl dipeptidyl aminopeptidase (PepX) in culture supernatants was measured by using the chromogenic substrate AlaPro- $p$-nitroanilid (BACHEM Feinchemicalien AG, Bubendorf, Switzerland) as described before (Steen et al. 2008).

AcmA activity was visualized on GM17 agar plates containing $0.2 \%(w / v)$ autoclaved, lyophilized M. lysodeikticus cells as halos around colonies after overnight growth at $30{ }^{\circ} \mathrm{C}$ (Buist et al. 1995).

\section{UV induction}

For UV induction of prophages, cultures were grown until an $\mathrm{OD}_{600}$ between 0.2 and 0.6 . The cells from $1 \mathrm{ml}$ of culture were collected by centrifugation and resuspended in $1 \mathrm{ml}$ of $1 \mathrm{mM} \mathrm{MgSO}_{4}$. The cell suspension was poured in a petri dish and exposed to UV light $(260 \mathrm{~nm})$ for $5 \mathrm{~s}$. Subsequently, $1 \mathrm{ml}$ of 2-fold concentrated GM17 containing $10 \mathrm{mM} \mathrm{CaCl}_{2}$ was added. Reduction of the $\mathrm{OD}_{600}$ was analysed in a microtiter plate reader (Molecular Devices Corporation, Menlo Oaks, $\mathrm{CA}$ ) for $4 \mathrm{~h}$.

\section{Results}

\section{A cell wall hydrolytic activity of $\sim 30 \mathrm{kDa}$ is present in $L$. lactis IL1403, but not in $L$. lactis MG1363}

Autolysis, as measured by the release of the intracellular Xprolyl dipeptidyl aminopeptidase activity into the culture supernatant, of L. lactis subsp. cremoris MG1363 and subsp. lactis IL1403 was examined during an incubation period of $78 \mathrm{~h}$ under identical conditions. This comparison revealed that the cells of strain IL1403 lysed to a higher extent than those of strain MG1363. Comparing the autolytic behaviour of the respective isogenic acmA mutants, by using a similar approach, showed that the acmA mutant of L. lactis IL1403 still lysed to some extent while the $L$. lactis MG1363 acmA mutant did not (Steen et al. 2008). The mutation in $a c m A$, the gene for the major lactococcal autolysin, had been obtained by an internal deletion in MG1363 and by an ISS1 transposon insertion in acmA of IL1403, and both strains had lost the AcmA PG hydrolase activity (Buist et al. 1995; Steen et al. 2008). In a plate assay for the detection of cell wall hydrolase activities by using M. lysodeikticus cell wall fragments as a substrate, no halo could be detected around colonies of the $\operatorname{acmA}$ insertion mutant of strain IL1403 (Fig. 1a). Zymographic analysis by using M. lysodeikticus or L. lactis cell wall fragments as a substrate showed that cell extracts of L. lactis IL1403acmA::ISS1 contain a lytic activity of around $30 \mathrm{kDa}$ 


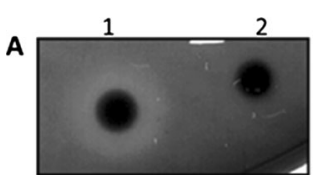

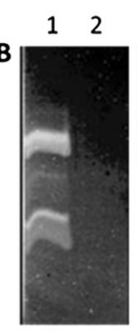

Sup

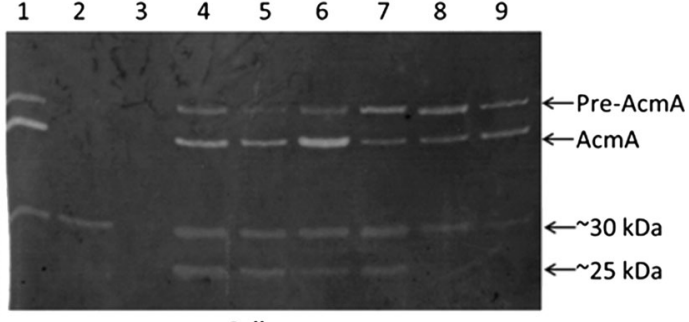

Cell
Fig. 1 Cell wall hydrolytic activities of L. lactis IL1403 and IL1403acmA::ISS1. a Plate assay of L. lactis IL1403 (1) and L. lactis IL1403acmA::ISS1 (2). b Zymographic analysis of supernatant (Sup) and cell fractions (Cell) of lactococcal strains L. lactis subsp. lactis

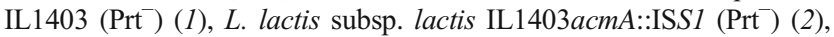
L. lactis subsp. cemoris MG1363acmA $\Delta 1$ (Prt $^{-}$) (3), L. lactis subsp. cremoris E8 (4), L. lactis subsp. cremoris E8 (Prt $\left.{ }^{-}\right)(5)$, L. lactis subsp. cremoris $\mathrm{HP}(6)$, L. lactis subsp. cremoris $\mathrm{HP}\left(\mathrm{Prt}^{-}\right)(7)$, L. lactis subsp. cremoris $\mathrm{Wg} 2(8)$ and L. lactis subsp. cremoris $\mathrm{Wg} 2$ (Prt $\left.{ }^{-}\right)$(9). In both assays, $0.15 \%$ M. lysodeikticus cell wall fragments was used as a substrate. Cell wall hydrolytic bands of (pre-)AcmA and the additional activities of $\sim 30$ and $\sim 25 \mathrm{kDa}$ are indicated in the right margin

which is not present in the supernatant fraction when renaturation was performed at pH 7.4 (Fig. 1b). In neither of these fractions of $L$. lactis MG1363acmA $\Delta l$ could a similar activity be detected (see lane 3 in Fig. 1b for the cell extract of MG1363). The band of $\sim 30 \mathrm{kDa}$ appeared after prolonged incubation and was always more intense when lactococcal cell instead of $M$. lysodeikticus wall fragments was used as a substrate (results not shown). The fact that the $\sim 30-\mathrm{kDa}$ lytic activity is still produced by the L. lactis IL1403 acmA mutant shows that it is not a degradation product of AcmA.

Zymographic analysis of cell and supernatant fractions of the L. lactis cremoris strains E8, HP and Wg2 and their PrtP protease-negative derivatives revealed that all three strains also contain an additional lytic activity of around $30 \mathrm{kDa}$ (Fig. 1b). Cells of strains E8 and HP also contain a cell wall hydrolase activity of approximately $25 \mathrm{kDa}$. The fact that the lytic activities are also detectable in the PrtP-negative derivatives indicates that they are not degradation products of AcmA, which is degraded by PrtP (Buist et al. 1998). The detected bands might be degradation products of AcmA caused by the extracellular surface protease, HtrA, albeit that those products have mostly been detected in supernatant fractions of L. lactis MG1363 and they were hardly able to bind to the cell walls of whole cells (Bosma et al. 2006; Steen et al. 2005a). The lytic activities of $\sim 30$ and $\sim 25 \mathrm{kDa}$ were only detected in the cell fractions.

The $\sim 30-\mathrm{kDa}$ cell wall hydrolase activity is present in the cytoplasm, the membrane and the cell wall of $L$. lactis IL1403 and L. lactis IL1403acmA::ISS1, but not in the

supernatant (Fig. 2). The highest activity was observed in the cell wall fraction. No processing of the cell wall hydrolase activity, as observed for pre-AcmA (see Fig. 1b), could be detected, suggesting that the enzyme lacks a signal peptide for secretion via the general Sec machinery (Buist et al. 2006).

\section{Genes for (predicted) PG hydrolases of $L$. lactis strains IL1403 and MG1363}

L. lactis has been suggested to possess 22 genes for putative PGHs based on PG hydrolase activity and cell wall binding domains (Layec et al. 2008). Literature searches and blast analyses showed that L. lactis IL1403 contains at least 18 genes for PG hydrolases (Table 2). From earlier studies, it is known that L. lactis MG1363 expresses the glucosaminidases AcmA, AcmB, AcmC and AcmD and the putative gamma-Dglutaminyl-L-lysyl-endopeptidase YjgB (Buist et al. 1995; Huard et al. 2004; Visweswaran et al. 2013). The genes for all five enzymes are present in the genome of IL1403 (Bolotin et al. 1999). BlastP analysis revealed that a second endopeptidase (encoded by $y p c D$ ) with an NlpC/P60 domain (Pfam PF00877) is present. The genome of IL1403 contains four genes $(a c m B, u s p 45, y f c F, y q e C)$ encoding putative amidases with a CHAP (cysteine, histidine-dependent amidohydrolases/peptidases) domain (Pfam PF05257). The gene $d a c B$ of MG1363 encodes a protein with L,D-carboxypeptidase activity that is involved in PG maturation (Courtin et al. 2006). Another D-Ala-D-Ala carboxypeptidase (DacA) of MG1363 converts a pentapeptide side chain in PG to a tetrapeptide side chain (Deghorain et al. 2010). Both dacA and $d a c B$ are present in IL1403. The L. lactis IL1403 genome contains four prophage-encoded lysin genes of which three homologues are encoded by the P335 phages bIL285,

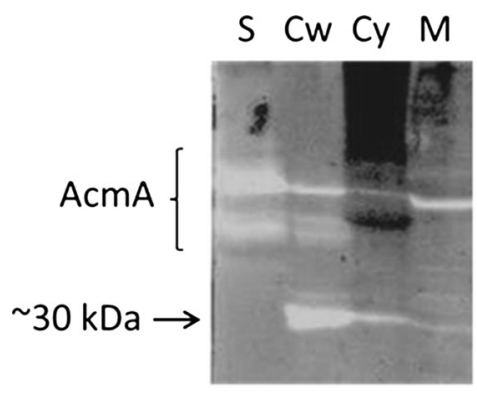

IL1403

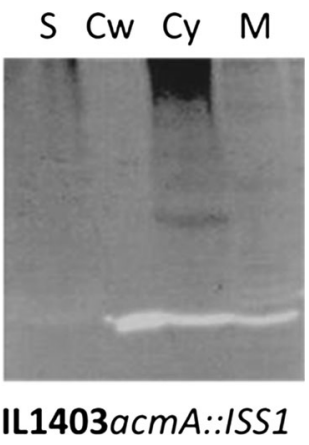

Fig. 2 Localization of cell wall hydrolytic activities in L. lactis strains IL1403 and IL1403acmA::ISS1. Proteins of cytoplasmic (Cy), membrane $(\mathrm{M})$, cell wall $(\mathrm{Cw})$ and supernatant $(\mathrm{S})$ fractions of both strains were prepared from overnight cultures and separated in a $12.5 \%$ SDS-PAA gel as described in the Materials and Methods section. The gel contained $0.3 \%(w / v)$ autoclaved cells of $L$. lactis IL1403 as a substrate. The various activity bands of (pre-)AcmA and their degradation products and the additional activity of $\sim 30 \mathrm{kDa}$ are indicated 


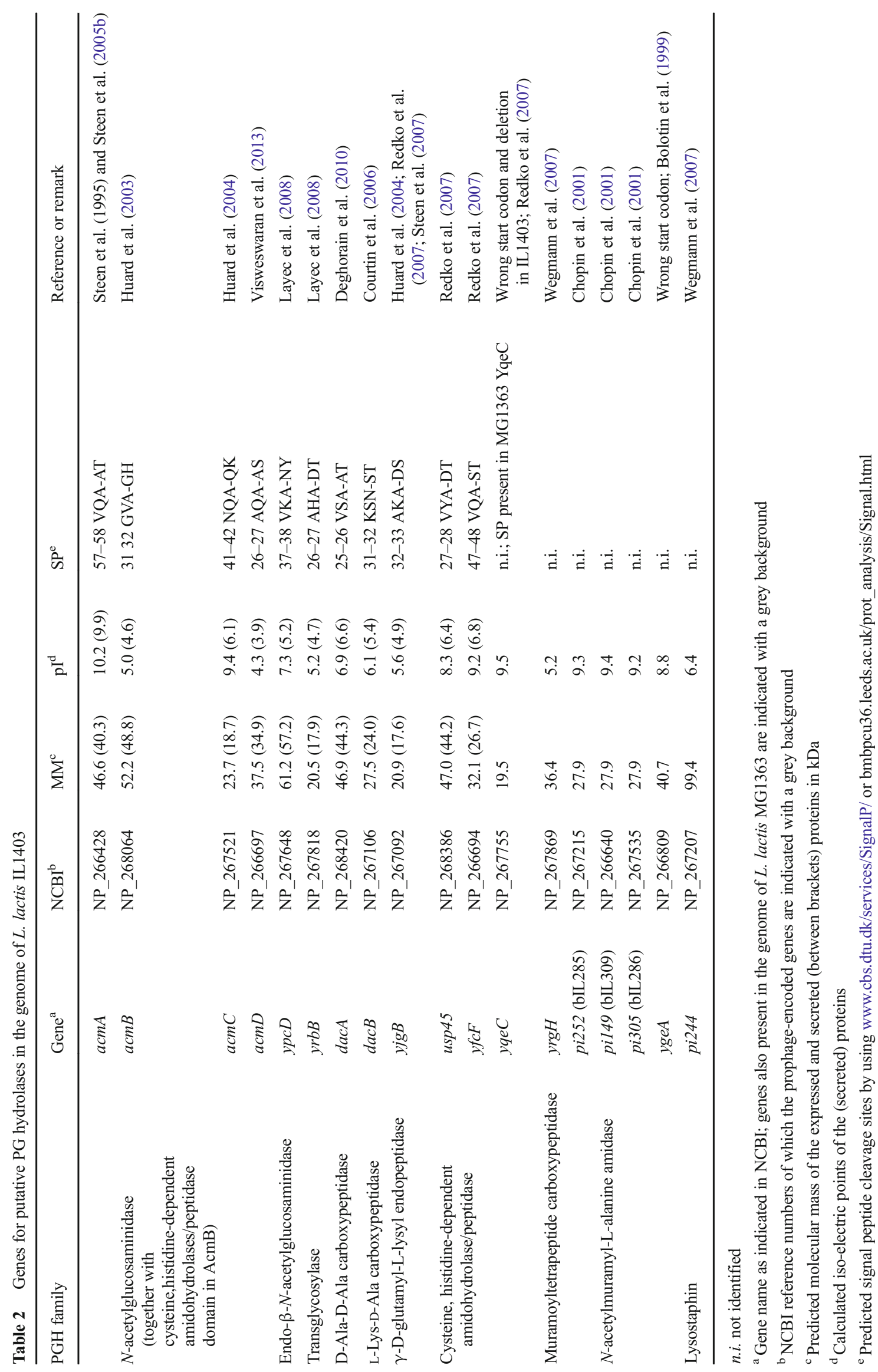


bIL286 and bIL309 (Chopin et al. 2001). The three phage lysins belong to the NLP/P60 family (pfam00877), contain an N-terminal active site domain and a C-terminal putative PG binding domain (pfam01471) (Labrie et al. 2004) and lack a predicted signal peptide for Sec-mediated secretion (Table 2). The comparison of these phage lysins shows that all are predicted to be $28-\mathrm{kD}$ a proteins, are nearly identical and are homologous to the endolysin ( $N$-acetylmuramoyl-L-alanine amidase) of phage BK5-T of L. lactis (Chopin et al. 2001). The fourth prophage encodes an endolysin with lysostaphin activity and a molecular mass of $99.4 \mathrm{kDa}$. These prophages are not present in the genome of MG1363 (Table 2, Wegmann et al. 2007). Blast analysis revealed that only the gene llmg_2005 (YP_001033263) encodes a protein that is homologous to the C-terminal part of the bIL lysins.

\section{The 30-kDa cell wall hydrolase activity in L. lactis IL1403 is phage encoded}

The comparison of the molecular masses of the predicted PG hydrolases of IL1403 suggests that $a c m D, y f c F, y r g H, d a c B$ or the endolysin genes pi252 (phage bIL285), pil49 (phage bIL309) or pi305 (phage bIL286) could all be responsible for the detected $\sim 30-\mathrm{kDa}$ PG hydrolytic activity. As acmD, $y f c F$ and $d a c B$ genes are also present in the genome of $L$. lactis MG1363 (Wegmann et al. 2007 and Table 2), it is unlikely that the $\sim 30-\mathrm{kDa}$ activity is encoded by these genes. As L. lactis MG1363 AcmD could only be detected in zymography by using a renaturation buffer of $\mathrm{pH}$ of 4 (Huard et al. 2004; Visweswaran et al. 2013), while the $\sim 30-\mathrm{kDa}$ activity was detectable at $\mathrm{pH}$ 7.4, the detected activity cannot be AcmD. Carboxypeptidases such as $y r g H$ do not damage to the integrity of the PG to the extent that they cause autolysis, and thus, $y r g H$ most likely does not specify the $\sim 30$-kDa lytic activity.

Based on this exclusion, the endolysins of bIL285, bIL286 or bIL309 could encode the detected activity. Previously, it was shown that expression of the lysin of bIL309 in L. lactis MG1363 resulted in increased lysis, but the molecular mass of the lysin and its cellular location were not investigated in this study (Steen et al. 2007). Here, we show that nisin-induced lysin of phage bIL309 in L. lactis NZ9000 (a derivative of MG1363) carrying plasmid pNGbil is only present in the cell fraction and that the active enzyme has a molecular mass of $\sim 30 \mathrm{kDa}$ (Fig. 3). This result indicates that the PG hydrolase activity of $\sim 30 \mathrm{kDa}$ in L. lactis IL1403 is a phage lysin and has a predicted molecular mass and pI of 27.9 and 9.2, respectively (Table 2). Because of the fact that the size of this endolysin is identical to that of the lysins of the phages bIL285 and bIL286, it is also possible that one or a combination of these enzymes is expressed in IL1403.

Induced expression of the phage endolysins from phages bIL285 and bIL286 in the L. lactis MG1363-derived acmA $h$ trA double mutant showed that these proteins are mainly

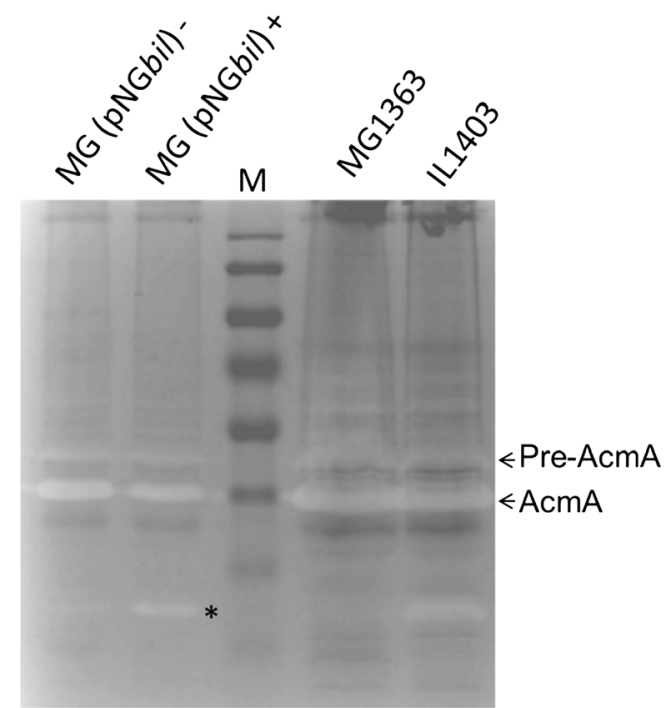

Fig. 3 Zymographic analysis of the cell wall hydrolase activity of the endolysin of phage bIL309. Cell-free extracts of L. lactis MG1363 (MG), L. lactis IL1403 (IL) and L. lactis MG1363 (pNGbil) from either nisininduced $(+)$ or uninduced $(-)$ cultures were separated in a $10 \%$ PAA gel which was subsequently renatured to detect the lytic activities. Bands of lytic activity of (pre-)AcmA and bIL309 endolysin (asterisks) are indicated. The gel contained $0.15 \%$ autoclaved, lyophilized M. lysodeikticus cells as a substrate

present in the cell fraction. Although the uninduced PA1001 strains did not lyse, lysis was observed for the induced strains expressing either of the endolysins as cellular proteins are present in the supernatant fractions of these strains (Suppl. Fig. S1). Because an $\sim 30-\mathrm{kDa}$ lytic activity was also detected in the L. lactis subsp. cremoris strains E8, HP and Wg2, a PCR on their chromosomal DNAs was performed by using primers specific for the endolysin genes of phages bIL285, bIL286 and bIL309 of IL1403 (Suppl. Table S1). PCR products of equal sizes were obtained for E8, HP, Wg2 and IL1403 indicating that the same endolysin genes are present in all four strains. Blast analysis by using the amino acid sequences of the endolysins encoded by pi252, pi305 or pi149 against the draft genome sequence of L. lactis subsp. cremoris HP (Lambie et al. 2014) showed that it encodes one endolysin with $96 \%$ identity (GenBank EUN34905). As expected, when chromosomal DNA of MG1363 was used as a template, no PCR product was obtained (results not shown).

These results show that a $\sim 30-\mathrm{kDa}$ PG hydrolase activity is encoded by one or more endolysin genes in L. lactis IL1403 and is expressed during exponential growth.

\section{bIL phages of $L$. lactis IL1403 are responsible for UV-induced lysis}

To investigate the contribution of the various endolysins in lysis of L. lactis IL1403, derivatives of IL1403 were used that lack parts of or the complete prophages bIL285, bIL286 and/or bIL309. L. lactis IL1946 is a derivative of 
IL1403 that was cured of bIL285 via insertion and excision of plasmid pE194 (Chopin et al. 1989). L. lactis IL2005 has partially lost phage bIL285 following the insertion of pE194, while prophage bIL286 is no longer inducible due to the insertion of an erythromycin resistance gene. L. lactis IL6047 is a derivative of strain IL2005 that has been cured of phage bIL309. The prophages of L. lactis IL1403 and its derivatives were induced through exposure to UV light. Strains IL1403, IL1403 $\mathrm{acmA}:$ :ISS1 and IL946 behaved similarly with respect to reduction of the $\mathrm{OD}_{600}$ and the release of the cytoplasmic peptidase PepX into the culture supernatant (Fig. 4). Although the reduction in $\mathrm{OD}_{600}$ of L. lactis IL2005 was less, the release of PepX is nearly similar.
No lysis was observed of L. lactis IL6047, which lacks the prophage bIL309, while bIL285 is partly deleted and bIL286 is not inducible (Fig. 4). The release of PepX under uninduced conditions was nearly the same for all strains (Fig. 4). Zymographic analysis showed that more phage lysin activity is present in the cell fractions of all strains upon UV treatment (Fig. 5). Endolysin activity is also detectable in L. lactis IL6047 (Fig. 5). As no phages are produced by this strain, this likely reduces cellular lysis (Fig. 5).

These results shown that the prophage bIL285, bIL286 and bIL309 contribute to cellular lysis upon phage induction by UV but also that phage lysins are expressed without UV induction.

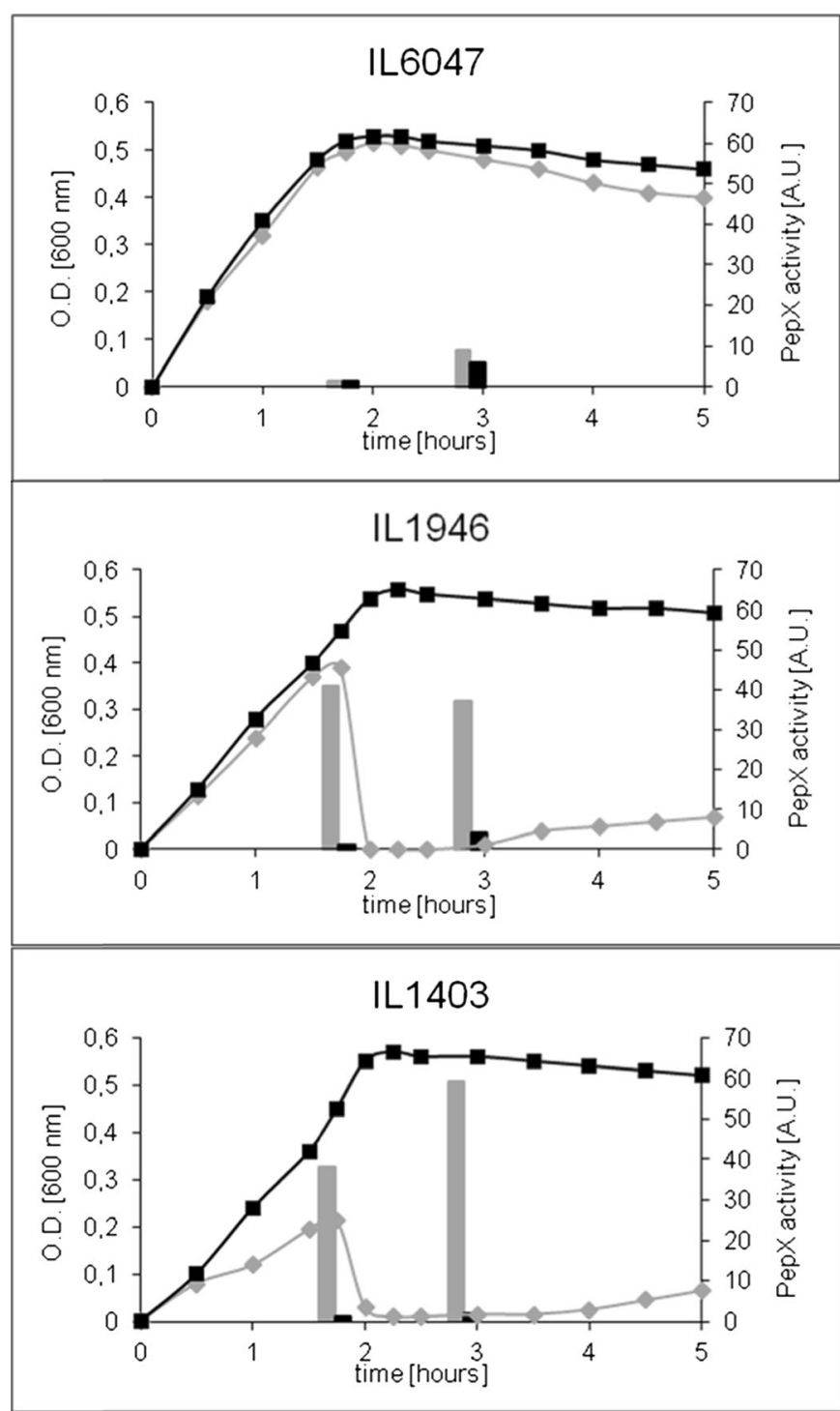

Fig. 4 Growth and lysis of L. lactis IL1403 and its prophage mutants. Growth of L. lactis strains IL6047, IL2005, IL1946, IL1403acmA::ISS1 and IL1403 was determined by measuring the $\mathrm{OD}_{600}$ (left Y-axis).
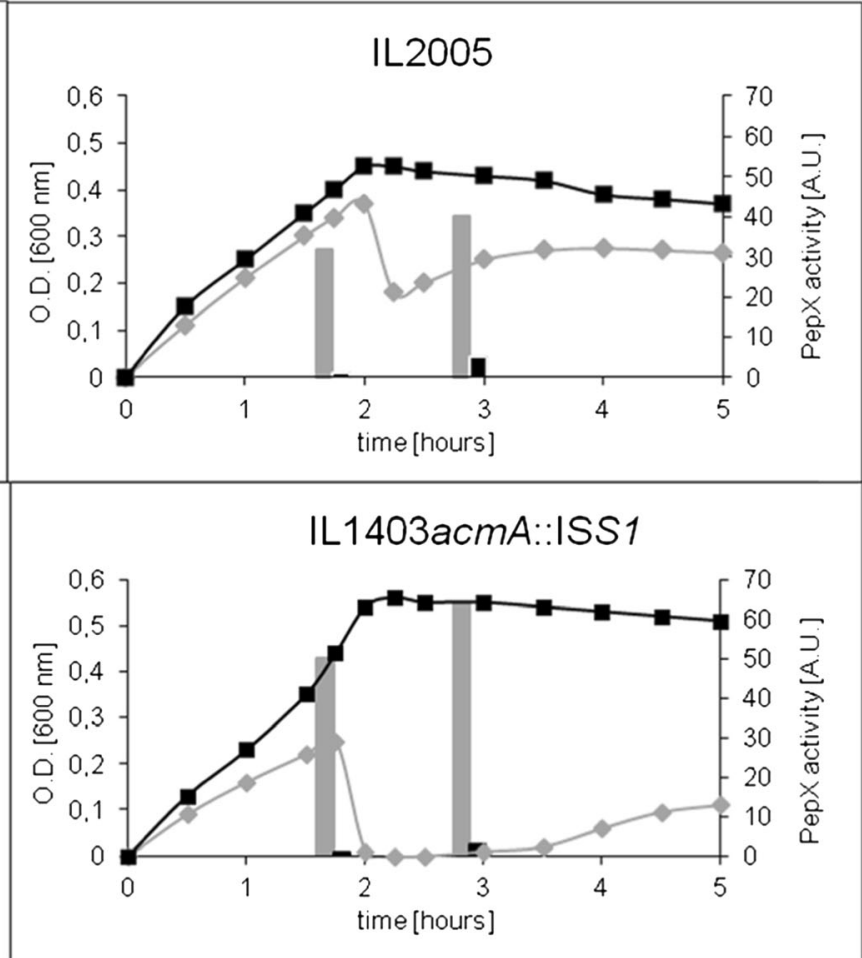

Autolysis after treatment with (grey bars) or without (black bars) UV was determined by measuring the release of the intracellular peptidase PepX (bars; in arbitrary units) into the culture supernatants (right Y-axis) 


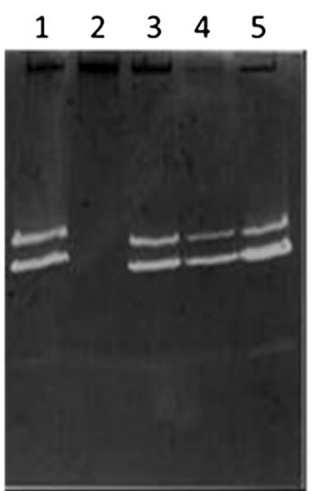

no UV

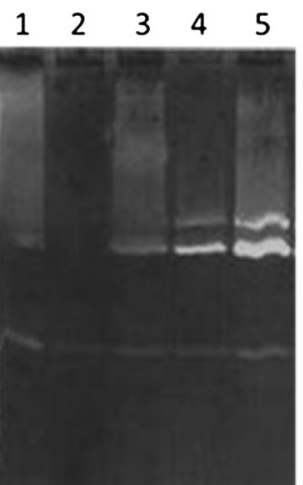

$1.5 \mathrm{~h}$ after UV

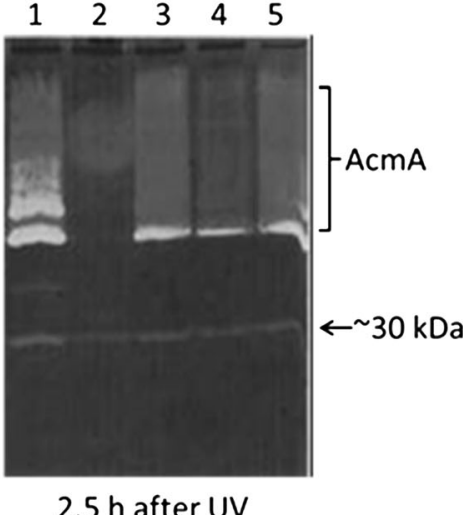

Fig. 5 Activity of AcmA and the endolysin of phage bIL309 before or after phage induction by UV treatment. Cell-free extracts of $L$. lactis IL1403 (1), IL1403acmA::ISS1 (2) and the isogenic prophage mutants L. lactis IL1946 (3), IL2005 (4) and IL6047 (5) were loaded on to a

\section{Transcription of prophage lysin genes during normal growth of $L$. lactis IL1403}

Detection of endolysin activity in cell extracts from exponential phase cells of L. lactis IL1403 implies that their genes are transcribed during growth. A RT-qPCR was performed to verify this assumption on RNA samples taken at mid-exponential phase from cultures of L. lactis IL1403 and its prophage mutant derivatives by using endolysin gene-specific primers (Suppl. Table S1). In L. lactis strains IL1403, IL1946 and IL2005, PCR products were obtained for all three endolysin genes (Fig. 6). This was not anticipated for IL1946 as it was reported to lack the bIL285 phage and its endolysin gene (Chopin et al. 1989). No transcript for the endolysin gene of bIL285 was seen in L. lactis IL6047, as expected (Fig. 6). These results show that the endolysin genes of the prophages bIL285, bIL286 and bIL309 are expressed during growth in
$12.5 \%$ SDS-PAA gel containing $0.15 \%$ autoclaved, lyophilized M. lysodeikticus cells as a substrate. Bands of lytic activity of (pre)AcmA and the $\sim 30-\mathrm{kDa}$ activity are indicated

GM17 although lysis as a consequence of UV-induced prophage production was not observed.

\section{Discussion}

In this paper, we show that $L$. lactis subsp. lactis IL1403 expresses a 27.9-kDa cellular and cell wall-located endolysin activity that is encoded by the phage lysin genes pi252, pi305 and pi149 of the prophages bIL285, bIL286 and bIL309, respectively. The endolysins contribute to autolysis of $L$. lactis subsp. cremoris MG1363, which lacks these prophages or homologous endolysin genes, lysed to a greater extent when the endolysin of phage bIL309 was overexpressed; zymographic analysis showed that this activity is similar in size to the 27.9-kDa activity detected in L. lactis IL1403. The endolysin genes of the three prophages are expressed during

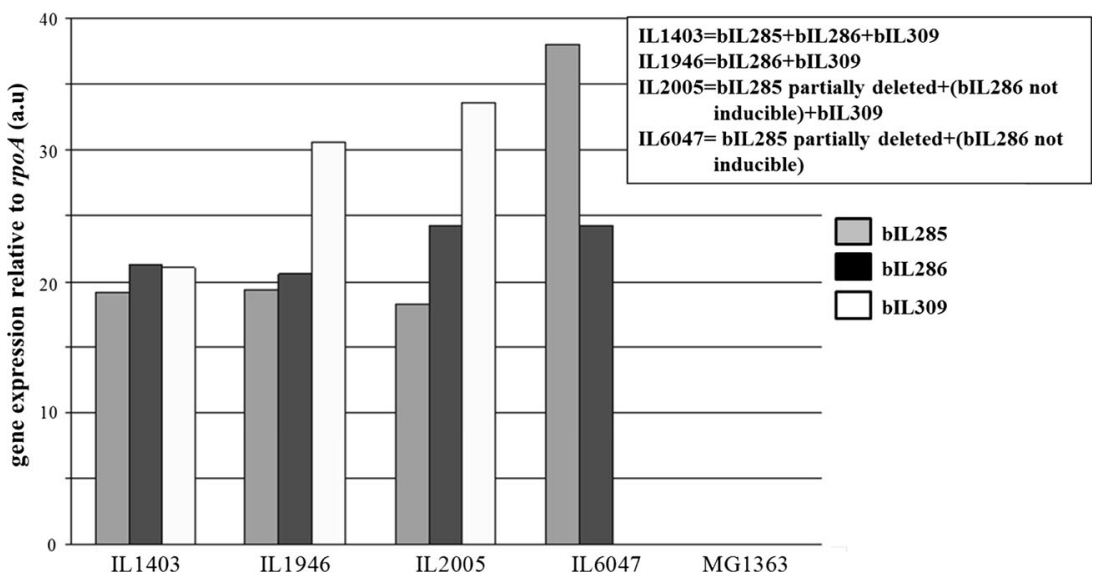

Fig. 6 Transcription of endolysin genes of bIL285 (grey bars), bIL286 (black bars) and bIL309 (white bars) in L. lactis IL1403 and its prophage mutants. RNA was isolated from L. lactis strains IL1403, IL1946, IL2005, IL6047 and MG1363 after overnight growth in GM17 at

$30{ }^{\circ} \mathrm{C}$. RT-qPCR was done with primers specific for each of the endolysin genes (Suppl. Table S1). Relative mRNA expression levels of different genes, normalized to that of the housekeeping gene for the RNA polymerase alpha subunit (rpoA), are indicated on the $Y$-axis 
growth of L. lactis IL1403 and contribute to autolysis. The expression of a similar-sized endolytic activity possibly encoded by homologous genes was detected in the natural strains L. lactis subsp. cremoris E8, Wg2 and HP that are used in cheese production.

Transcripts of pi252, pi305 and pi149 were detected by RTqPCR in L. lactis IL1403 but not in L. lactis MG1363, which lacks the homologous endolysin genes (Wegmann et al. 2007) and does not produce a $\sim 30-\mathrm{kDa}$ lytic cell wall hydrolase activity. The analysis of the phage deletion and interruption mutants of L. lactis IL1403 shows that all three endolysins contribute to cellular lysis. The 27.9-kDa endolysin activity was present in the cell wall fraction but was not detectable in the supernatant, suggesting that the endolysins, which lack a signal peptide, might be secreted but after translocation are entrapped in the cell wall. The endolysin genes pi252, pi149 and pi305 are all followed by a gene encoding a pore-forming holin required for secretion of the signal peptide-less phage lysins (Redko et al. 2007). Whether the holin genes are also expressed during growth and contribute to the secretion of the endolysins remains to be investigated. It is also possible that initial lysis is caused by other autolysins such as AcmB or $\mathrm{AcmD}$ and that this results in the release of cytoplasmic endolysins. It has been shown that overexpression of phage lysins without their corresponding holins can result in efficient and enhanced cell lysis of L. lactis (Steen et al. 2007). Induced expression of the bIL309, bIL285 or bIL286 endolysin in L. lactis MG1363acmA $\Delta 1$ resulted in a cumulative effect on lysis. Also, analysis of prophage deletion and insertion mutants of L. lactis IL1403 showed that the increased lysis phenotype of IL1403 is the result of the collective activity of the phage lysins.

The fact that the endolysins or their activity was not detectable in the culture supernatant can be explained by the fact that the C-terminal 60 amino acids of the phage lysins of bIL309, bIL285 or bIL286 encompass a putative PG_binding_1 PG binding domain (pfam01471) that has also been identified in other phage lysins (Labrie et al. 2004). A similar type of binding domain in the Bacillus anthracis germination-specific lytic enzyme SleB has been shown to bind PG (Heffron et al. 2011).

The identified endolysins seem to be widely present in L. lactis strains as was shown for the dairy strains $\mathrm{E} 8, \mathrm{Wg} 2$ and HP. Blast analysis against the GenBank database by using the amino acid sequences of the endolysins encoded by pi252, pi305 and pi149 showed that the genes for homologous endolysins are mostly present in the genomes of L. lactis subsp. lactis, although they can also be found in genomes from the subsp. cremoris and subsp. lactis biovar diacetylactis. Multiple copies encoding homologues of this endolysin could only be detected in the genome sequences of L. lactis subsp. lactis. For instance, the human isolate L. lactis subsp. lactis CV56 contains three homologous phage lysin genes (ADZ64727, ADZ64454, ADZ63676) (Gao et al. 2011), while the genomes of strains SK11 (Makarova et al. 2006) and A12 (Passerini et al. 2013) each contain one homologous endolysin gene (ABJ73565 and CDG04098, respectively). The plant-derived L. lactis KF147 strain does not possess any homologous endolysin genes.

A comparison of the PG hydrolytic activity of the highly autolytic L. lactis subsp. cremoris strain 2250 and its acmA deletion derivative revealed that, next to AcmA, extra minor and smaller lytic activities are present that were absent in similar samples from L. lactis MG1363 (Riepe et al. 1997). These activities were suggested to act in conjunction with AcmA to cause the lysis phenotype of L. lactis 2250. Like the endolysin activities specified by the prophage bIL285, bIL286 and/or bIL309, the cell walldegrading activity in L. lactis 2250 was also shown to be more specific for cell wall fragments of L. lactis than those of M. lysodeikticus.

Not only did we identify homologous endolysin genes in the natural strains $\mathrm{Wg} 2, \mathrm{E} 8$ and $\mathrm{HP}$, an activity of $\sim 25 \mathrm{kDa}$ was also present in the cell fractions of the latter two strains. Analysis of the draft genome sequence of $L$. lactis subsp. cremoris HP (Lambie et al. 2014) revealed two genes (GenBank EUN34017.1 and EUN33988.1) encoding homologous endolysins with calculated molecular masses of $20.5 \mathrm{kDa}$ that could explain the activity band of $\sim 25 \mathrm{kDa}$. This natural expression of phage lysins during growth might be a desired feature for the selection of natural L. lactis strains for the production of cheese in order to increase the release of intracellular peptidases needed for enhanced cheese ripening. Screening for these activities might help in the selection of preferred strains for usage in cheese production.

Acknowledgments We thank Anne de Jong for advice and support on the computer work, Henk Mulder for preparing the photographs and Marie-Christine Chopin (INRA, Biotec., Jouy-en-Josas, France) for the phage deletion derivatives of L. lactis IL1403, strains IL1946, IL2005 and IL6047.

\section{Compliance with ethical standard}

Conflict of interest All the authors declare that he/she has no conflict of interest.

Ethical approval This article does not contain any studies with human participants or animals performed by any of the authors.

Open Access This article is distributed under the terms of the Creative Commons Attribution 4.0 International License (http:// creativecommons.org/licenses/by/4.0/), which permits unrestricted use, distribution, and reproduction in any medium, provided you give appropriate credit to the original author(s) and the source, provide a link to the Creative Commons license, and indicate if changes were made. 


\section{References}

Bolotin A, Mauger S, Malarme K, Ehrlich SD, Sorokin A (1999) Lowredundancy sequencing of the entire Lactococcus lactis IL1403 genome. Antonie Van Leeuwenhoek 76:27-76

Bosma T, Kanninga R, Neef J, Audouy SAL, van Roosmalen ML, Steen A, Buist G, Kok J, Kuipers OP, Robillard G, Leenhouts K (2006) Novel surface display system for proteins on non-genetically modified gram-positive bacteria. Appl Environ Microbiol 72:880-890

Buist G, Kok J, Leenhouts KJ, Dabrowska M, Venema G, Haandrikman AJ (1995) Molecular cloning and nucleotide sequence of the gene encoding the major peptidoglycan hydrolase of Lactococcus lactis, a muramidase needed for cell separation. J Bacteriol 177:1554-1563

Buist G, Karsens H, Nauta A, van Sinderen D, Venema G, Kok J (1997) Autolysis of Lactococcus lactis caused by induced overproduction of its major autolysin, AcmA. Appl Environ Microbiol 63:2722-2728

Buist G, Venema G, Kok J (1998) Autolysis of Lactococcus lactis is influenced by proteolysis. J Bacteriol 180:5947-5953

Buist G, Ridder ANJA, Kok J, Kuipers OP (2006) Different subcellular locations of secretome components of gram-positive bacteria. Microbiol (Reading, Engl) 152:2867-2874

Buist G, Steen A, Kok J, Kuipers OP (2008) LysM, a widely distributed protein motif for binding to (peptido)glycans. Mol Microbiol 68: $838-847$

Chopin A, Chopin MC, Moillo-Batt A, Langella P (1984) Two plasmiddetermined restriction and modification systems in Streptococcus lactis. Plasmid 11:260-263

Chopin MC, Chopin A, Rouault A, Galleron N (1989) Insertion and amplification of foreign genes in the Lactococcus lactis subsp. lactis chromosome. Appl Environ Microbiol 55:1769-1774

Chopin A, Bolotin A, Sorokin A, Ehrlich SD, Chopin M (2001) Analysis of six prophages in Lactococcus lactis IL1403: different genetic structure of temperate and virulent phage populations. Nucleic Acids Res 29:644-651

Courtin P, Miranda G, Guillot A, Wessner F, Mézange C, Domakova E, Kulakauskas S, Chapot-Chartier M-P (2006) Peptidoglycan structure analysis of Lactococcus lactis reveals the presence of an L,Dcarboxypeptidase involved in peptidoglycan maturation. J Bacteriol 188:5293-5298

Deghorain M, Fontaine L, David B, Mainardi J-L, Courtin P, Daniel R, Errington J, Sorokin A, Bolotin A, Chapot-Chartier M-P, Hallet B, Hols P (2010) Functional and morphological adaptation to peptidoglycan precursor alteration in Lactococcus lactis. J Biol Chem 285: 24003-24013

Gao Y, Lu Y, Teng K-L, Chen M-L, Zheng H-J, Zhu Y-Q, Zhong J (2011) Complete genome sequence of Lactococcus lactis subsp. lactis CV56, a probiotic strain isolated from the vaginas of healthy women. J Bacteriol 193:2886-2887

Gasson MJ (1983) Plasmid complements of Streptococcus lactis NCDO 712 and other lactic streptococci after protoplast-induced curing. J Bacteriol 154:1-9

Heffron JD, Sherry N, Popham DL (2011) In vitro studies of peptidoglycan binding and hydrolysis by the Bacillus anthracis germinationspecific lytic enzyme SleB. J Bacteriol 193:125-131

Huard C, Miranda G, Wessner F, Bolotin A, Hansen J, Foster SJ, ChapotChartier M-P (2003) Characterization of AcmB, an Nacetylglucosaminidase autolysin from Lactococcus lactis. Microbiol (Reading, Engl) 149:695-705

Huard C, Miranda G, Redko Y, Wessner F, Foster SJ, Chapot-Chartier M-P (2004) Analysis of the peptidoglycan hydrolase complement of Lactococcus lactis: identification of a third $\mathrm{N}$-acetylglucosaminidase, AcmC. Appl Environ Microbiol 70:3493-3499

Kok J (1990) Genetics of the proteolytic system of lactic acid bacteria. FEMS Microbiol Rev 7:15-42
Kok J, van Dijl JM, van der Vossen JM, Venema G (1985) Cloning and expression of a Streptococcus cremoris proteinase in Bacillus subtilis and Streptococcus lactis. Appl Environ Microbiol 50:94-101

Kuipers OP, Beerthuyzen MM, Siezen RJ, De Vos WM (1993) Characterization of the nisin gene cluster nisABTCIPR of Lactococcus lactis. Requirement of expression of the nisA and nisI genes for development of immunity. Eur J Biochem 216:281291

Kuipers OP, de Ruyter PGGA, Kleerebezem M, de Vos WM (1998) Quorum sensing-controlled gene expression in lactic acid bacteria. J Biotechnol 64:15-21

Labrie S, Vukov N, Loessner MJ, Moineau S (2004) Distribution and composition of the lysis cassette of Lactococcus lactis phages and functional analysis of bacteriophage ul36 holin. FEMS Microbiol Lett 233:37-43

Lambie SC, Altermann E, Leahy SC, Kelly WJ (2014) Draft genome sequence of Lactococcus lactis subsp. cremoris HPT, the first defined-strain dairy starter culture bacterium. Genome Announc 2(2):e00107-e00114

Layec S, Decaris B, Leblond-Bourget N (2008) Diversity of Firmicutes peptidoglycan hydrolases and specificities of those involved in daughter cell separation. Res Microbiol 159:507-515

Leenhouts KJ and Venema G (1993) Lactococcal plasmid vectors. In K. G. Hardy (Ed.), Plasmids. A practical approach (pp. 66-94). Oxford University Press, New York.

Makarova K, Slesarev A, Wolf Y, Sorokin A, Mirkin B, Koonin E, Pavlov A, Pavlova N, Karamychev V, Polouchine N, Shakhova V, Grigoriev I, Lou Y, Rohksar D, Lucas S, Huang K, Goodstein DM, Hawkins T, Plengvidhya V, Welker D, Hughes J, Goh Y, Benson A, Baldwin K, Lee J-H, DíazMuñiz I, Dosti B, Smeianov V, Wechter W, Barabote R, Lorca G, Altermann E, Barrangou R, Ganesan B, Xie Y, Rawsthorne H, Tamir D, Parker C, Breidt F, Broadbent J, Hutkins R, O'Sullivan D, Steele J, Unlu G, Saier M, Klaenhammer T, Richardson P, Kozyavkin S, Weimer B, Mills D (2006) Comparative genomics of the lactic acid bacteria. Proc Natl Acad Sci U S A 103:15611-15616

Meyrand M, Boughammoura A, Courtin P, Mézange C, Guillot A, Chapot-Chartier M-P (2007) Peptidoglycan N-acetylglucosamine deacetylation decreases autolysis in Lactococcus lactis. Microbiol (Reading, Engl) 153:3275-3285

Passerini D, Coddeville M, Le Bourgeois P, Loubière P, Ritzenthaler P, Fontagné-Faucher C, Daveran-Mingot M-L, Cocaign-Bousquet $\mathrm{M}$ (2013) The carbohydrate metabolism signature of lactococcus lactis strain A12 reveals its sourdough ecosystem origin. Appl Environ Microbiol 79:5844-5852

Redko Y, Courtin P, Mézange C, Huard C, Chapot-Chartier M-P (2007) Lactococcus lactis Gene yjgB encodes a $\gamma$-d-glutaminyl-1-lysyl-endopeptidase which hydrolyzes peptidoglycan. Appl Environ Microbiol 73:5825-5831

Riepe HR, Pillidge CJ, Gopal PK, McKay LL (1997) Characterization of the highly autolytic Lactococcus lactis subsp. cremoris strains CO and 2250. Appl Environ Microbiol 63:3757-3763

Steen A, Buist G, Leenhouts KJ, El Khattabi M, Grijpstra F, Zomer AL, Venema G, Kuipers OP, Kok J (2003) Cell wall attachment of a widely distributed peptidoglycan binding domain is hindered by cell wall constituents. J Biol Chem 278:23874-23881

Steen A, Buist G, Horsburgh GJ, Venema G, Kuipers OP, Foster SJ, Kok $\mathrm{J}$ (2005a) AcmA of Lactococcus lactis is an $\mathrm{N}$ acetylglucosaminidase with an optimal number of LysM domains for proper functioning. FEBS J 272:2854-2868

Steen A, Palumbo E, Deghorain M, Cocconcelli PS, Delcour J, Kuipers OP, Kok J, Buist G, Hols P (2005b) Autolysis of Lactococcus lactis is increased upon D-alanine depletion of peptidoglycan and lipoteichoic acids. J Bacteriol 187:114-124 
Steen A, van Schalkwijk S, Buist G, Twigt M, Szeliga M, Meijer W, Kuipers OP, Kok J, Hugenholtz J (2007) Lytr, a phage-derived amidase is most effective in induced lysis of Lactococcus lactis compared with other lactococcal amidases and glucosaminidases. Int Dairy J 17:926-936

Steen A, Buist G, Kramer NE, Jalving R, Benus GFJD, Venema G, Kuipers OP, Kok J (2008) Reduced lysis upon growth of Lactococcus lactis on galactose is a consequence of decreased binding of the autolysin AcmA. Appl Environ Microbiol 74:4671-4679

Towbin H, Staehelin T, Gordon J (1979) Electrophoretic transfer of proteins from polyacrylamide gels to nitrocellulose sheets: procedure and some applications. Proc Natl Acad Sci U S A 76:4350-4354

Veiga P, Bulbarela-Sampieri C, Furlan S, Maisons A, Chapot-Chartier MP, Erkelenz M, Mervelet P, Noirot P, Frees D, Kuipers OP, Kok J, Gruss A, Buist G, Kulakauskas S (2007) SpxB regulates O- acetylation-dependent resistance of Lactococcus lactis peptidoglycan to hydrolysis. J Biol Chem 282:19342-19354

Visweswaran GRR, Steen A, Leenhouts K, Szeliga M, Ruban B, Hesseling-Meinders A, Dijkstra BW, Kuipers OP, Kok J, Buist G (2013) AcmD, a homolog of the major autolysin AcmA of Lactococcus lactis, binds to the cell wall and contributes to cell separation and autolysis. PLoS One 8:e72167

Vollmer W, Joris B, Charlier P, Foster S (2008) Bacterial peptidoglycan (murein) hydrolases. FEMS Microbiol Rev 32:259-286

Wegmann U, O'Connell-Motherway M, Zomer A, Buist G, Shearman C, Canchaya C, Ventura M, Goesmann A, Gasson MJ, Kuipers OP, van Sinderen D, Kok J (2007) Complete genome sequence of the prototype lactic acid bacterium Lactococcus lactis subsp. cremoris MG1363. J Bacteriol 189:3256-3270

Young R (2002) Bacteriophage holins: deadly diversity. J Mol Microbiol Biotechnol 4:21-36 